\title{
Effect of Exercise on Mental Health in the Physical Dimension, Anxiety and Mental Disorder, Social Dysfunction and Depression
}

\author{
Morteza Alibakhshi Kenari \\ Martyr Beheshti University of Medical Sciences and Health Services, Tehran, Iran \\ Email: Morteza.alibakhshikenari@gmail.com
}

Received 26 December 2013; revised 26 January 2014; accepted 4 February 2014

Copyright (C) 2014 by author and Scientific Research Publishing Inc. This work is licensed under the Creative Commons Attribution International License (CC BY). http://creativecommons.org/licenses/by/4.0/

\section{(c) (i) Open Access}

\begin{abstract}
In the last twenty years, a lot of attention to issues of psychology and psychotherapy are associated with physical activity. Due to the increasing rate of mental disorders in country, this study attempts to compare the health of athletes and non-athletes in Beheshti University. Mental Health in schools will also compare. In this study, the health measured using the General Health Questionnaire GHQ-28 has performed. University students participated in this study of 260 patients who were randomly selected to represent the school. Statistical methods are used for the analysis and comparison of two sample t-test. The results show that the significant differences of symptoms of physical, anxiety, sleep disorder, social dysfunction and depression in the two groups were observed between athletes and non-athletes. The college student mental health and physical education than other students in four scales were much more favorable situation.
\end{abstract}

\section{Keywords}

Exercise; Physical Dimension; Anxiety and Sleep Disorders; Depression; Mental Health; Impaired Social Functioning

\section{Introduction}

In recent years much attention has been psychological and psychotherapy, because people today are more than anything suffering from mental health problems. Now in the world, especially in developing countries, about 150 million people suffer from some form of mental disorder. These figures are somewhat higher population 
growth and changes in lifestyle and family breakdown and economic problems involved. One of the ways that psychologists have identified a role for the reduction and treatment in mental health is exercise (McGannon \& Poon, 2005). In other words, the researchers found a strong link between exercise and mental health and mental disorder there. Since our country is a developing country and the future of the students and mothers of tomorrow and the search for identity and age may be due to various reasons such as being away from family and feel more responsibility and career and marriage and other issues have been under a lot of stress and trauma are at risk. It is important to note. Obviously neglecting their health status may be irreparable damage to the family that they formed under the direct supervision and follow it to the community (Humphreys, 2003).

\section{Health and Mental Tension}

The World Health Organization defines mental health state of complete physical, mental and social be called (WHO, 2007). Some psychologists believe that the ability and flexibility to adapt to the environment and the judge denied and fair and reasonable in the face of mental health and psychological criteria (Knechtle, 2004). And treatment of mental illness as well as social and family life and enable compatibility of environmental. It should be noted that those with no mental disorder but its necessarily mentally healthy people to account, just as those who have no mental disease but are not considered to be healthy (Pereira, 2007).

Stress is a condition in which the emotions and expressions of the human body comes into tension and heaviness. To say to the stress of the human capacity for doing work that requires mental focus as well as the weakening of the human forces that began to fatigue.

\section{The Role of Exercise in Mental Health Care}

Studies on the effect of exercise on mental health in children have found that play an important role in maintaining the health of sick children's physical activity (Matsudo, 2006). According to a study conducted in 1991 also found that aerobic exercise is an important factor in reducing the effects of stress (Samad, 2004). In addition, it was found most effective exercise in elderly hospitalized and non-hospitalized alleviate symptoms of anxiety, depression, mood and stress reactions, as well as aerobic exercise is important for stress reduction (Brunner \& Suddarth, 2004). In 1990 it was found exercise improves mood and mental health and increased self-esteem and self-respect, Bornak and colleagues (1995) found that intense exercise can have many benefits on mood and behavior and reduce stress and increase self-esteem and aerobic exercise may improve the self-esteem of dust.

\section{Materials and Methods}

This research is a descriptive search. Beheshti University student population with a bachelor's or master's in school year 2013 were enrolled in MQT form. The number of participants is 260 persons who comprise 80 individual athletes and 180 non-athletes. These were in addition to several sports teams of the members of the group selected College of Engineering and Physical education and art and literature and science and theology and psychology and social science has been formed, which were randomly selected.

The instrument used in this research questionnaire is 28 questions, $\{\mathrm{GHq} 28\}$ is a standard tool designed by Goldberg and Hiller. This questionnaire was formed of 28 questions to ask first eight physical symptoms and eight second question anxiety and eight third question of social dysfunction and Eight quarters of the symptoms of depression and sleep disturbances were assessed. To compare the mental health of athletes and non-athletes of all indices $t$ test for independent groups was used. All statistical calculations were performed using computer SPSS software.

\section{Results and Findings}

After statistical analysis and hypothesis testing, research findings revealed significant differences in mental health status than non-athlete student athlete "as shown in table". The problem in all dimensions: physical symptoms of anxiety and sleep disorder symptoms, social functioning and depressive symptoms compared to non-athletes were better $\{\mathrm{p}<0 / 05\}$ "as shown in Table 1".

Considering the above table mental health scores of athletes is very better than non-athletes "as shown in Table 2".

According to information found in each of the four scale athletes are a more favorable situation as shown in Figure 1. 
Table 1. Scores on mental health subjects.

\begin{tabular}{cccc}
\hline & ATHLETES & \multicolumn{2}{c}{ NON-ATHLETES } \\
\hline mean & Standard deviation & mean & Standard deviation \\
19.81 & 11.94 & 24.94 & 15.26 \\
\hline
\end{tabular}

Table 2. Scores on the four scales the mental health in the participants.

\begin{tabular}{ccccccccc}
\hline \multicolumn{2}{c}{ Depression } & \multicolumn{2}{c}{$\begin{array}{l}\text { Impairment in social } \\
\text { functioning }\end{array}$} & \multicolumn{2}{c}{$\begin{array}{c}\text { Anxiety and sleep } \\
\text { disorders }\end{array}$} & \multicolumn{3}{c}{ Physical } \\
\hline $\begin{array}{l}\text { Standard } \\
\text { deviation }\end{array}$ & mean & $\begin{array}{l}\text { Standard } \\
\text { deviation }\end{array}$ & mean & $\begin{array}{l}\text { Standard } \\
\text { deviation }\end{array}$ & mean & $\begin{array}{c}\text { Standard } \\
\text { deviation }\end{array}$ & mean & Index \\
3.38 & 4.14 & 4.01 & 5.58 & 3.43 & 5.13 & 2.38 & 4.3 & ATHLETES \\
3.41 & 5.18 & 4.84 & 7.01 & 3.81 & 6.5 & 399 & 6.31 & NON-ATHLETES \\
\hline
\end{tabular}

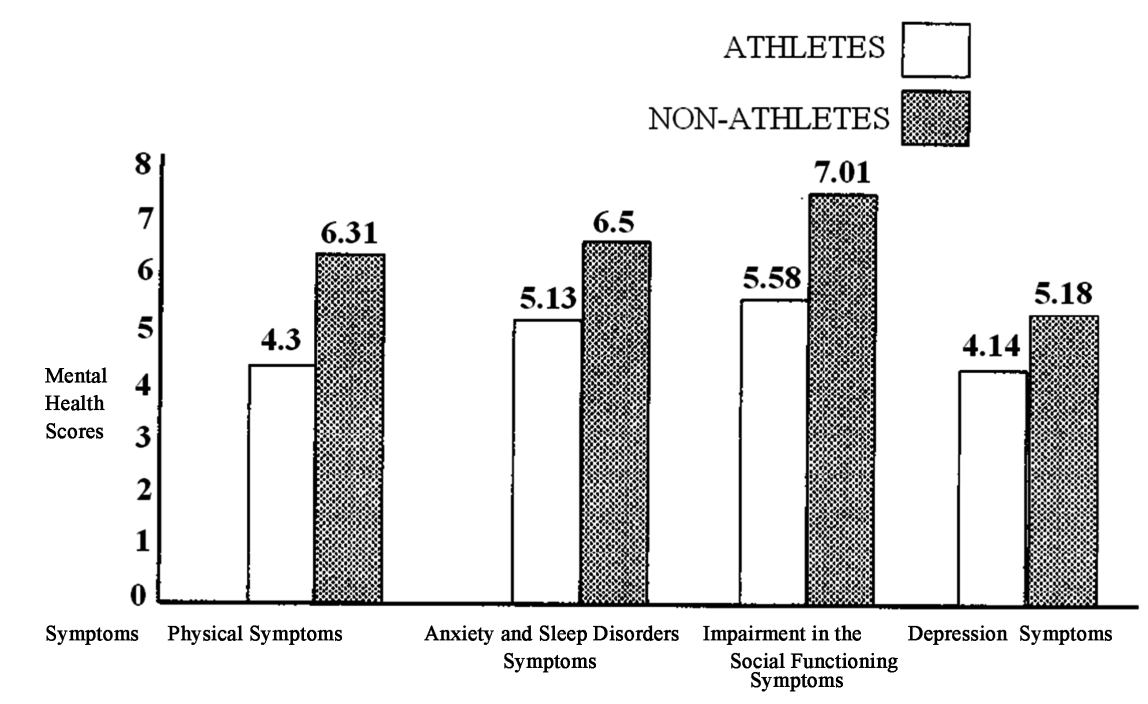

Figure 1. Comparison of four scales_in the student-athletes and non-athletes.

In this study, four mental health scales were calculated separately for the eight colleges as shown in Figure 2.

So that diagram 2 is shown the Students School of Physical Sciences and Engineering and Theology and social sciences, art and psychology of better mental health. The results of the four mental health scales were also segregated schools. Charts tree showing physical signs to separate colleges as shown in Figure 3.

As can be seen in terms of physical symptoms and physical health of college students Theological and Literary physical and engineering sciences and social sciences, and arts and psychology in order to have been better. Results from four mental health scales and symptoms of anxiety and sleep disorders are divided into the following four graphs as shown in Figure 4.

Based on these findings in terms of anxiety and sleep disorders in college students Physical and engineering and social sciences, art, literature and psychology were better the situation. The results of the four measures of mental health symptoms and social dysfunction are shown in Figure 5.

Diagram 6 to four measures of mental health symptoms in schools heaven compared to that. According to diagram 6 is characterized by symptoms of depression in the Schools Physical and engineering sciences and social sciences and psychology, theology, literature and art are in a more favorable situation as shown in Figure 6.

Six charts revealed that symptoms of depressive in The School of Physical Education, Engineering, Theology, Literature, Science, Social Sciences, Psychology and art are in a more favorable situation.

\section{Conclusion}

Data collection and statistical analysis of the results suggest that student athletes compared to non-athletic 


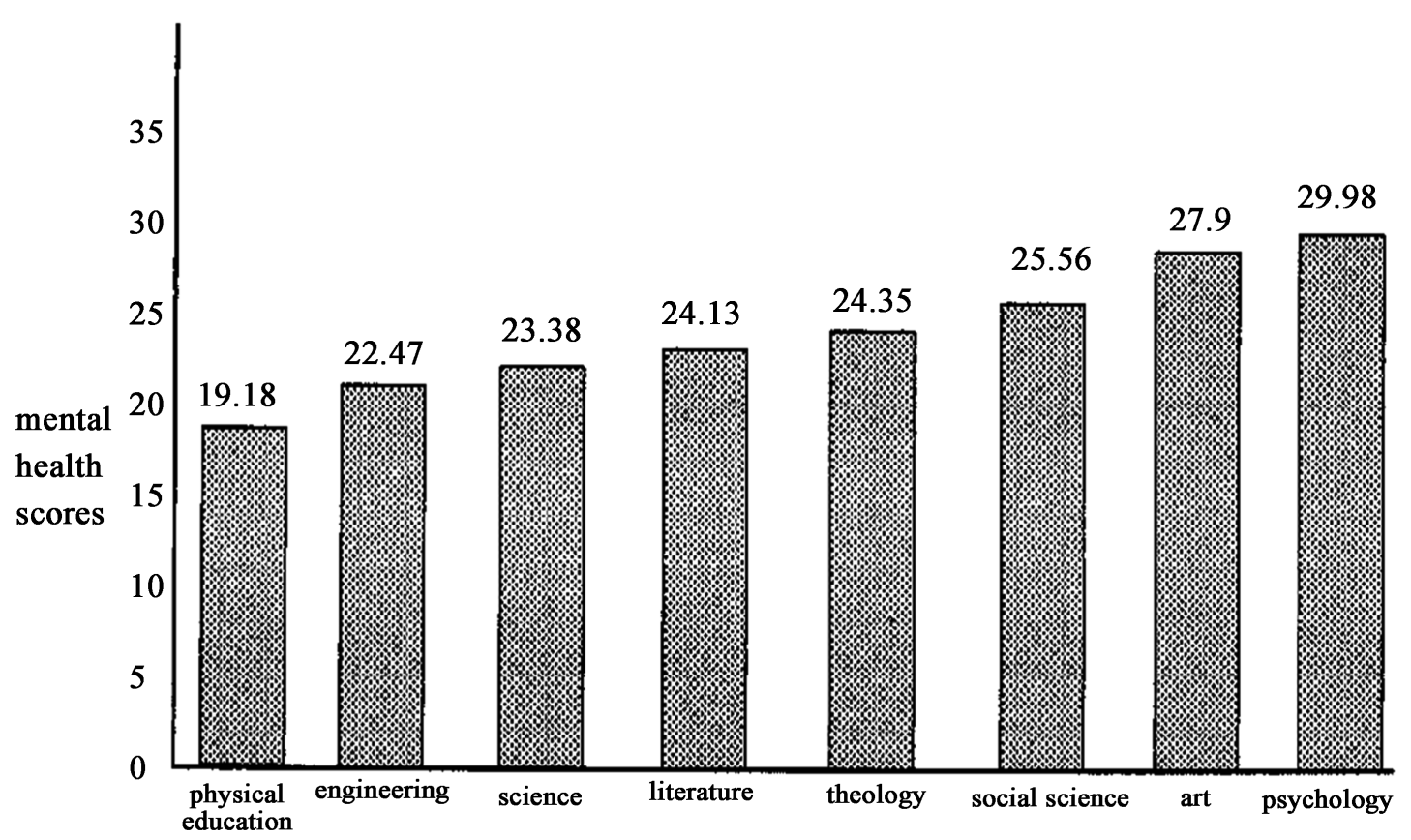

field of study

Figure 2. Comparison of the mental health divided into faculty.

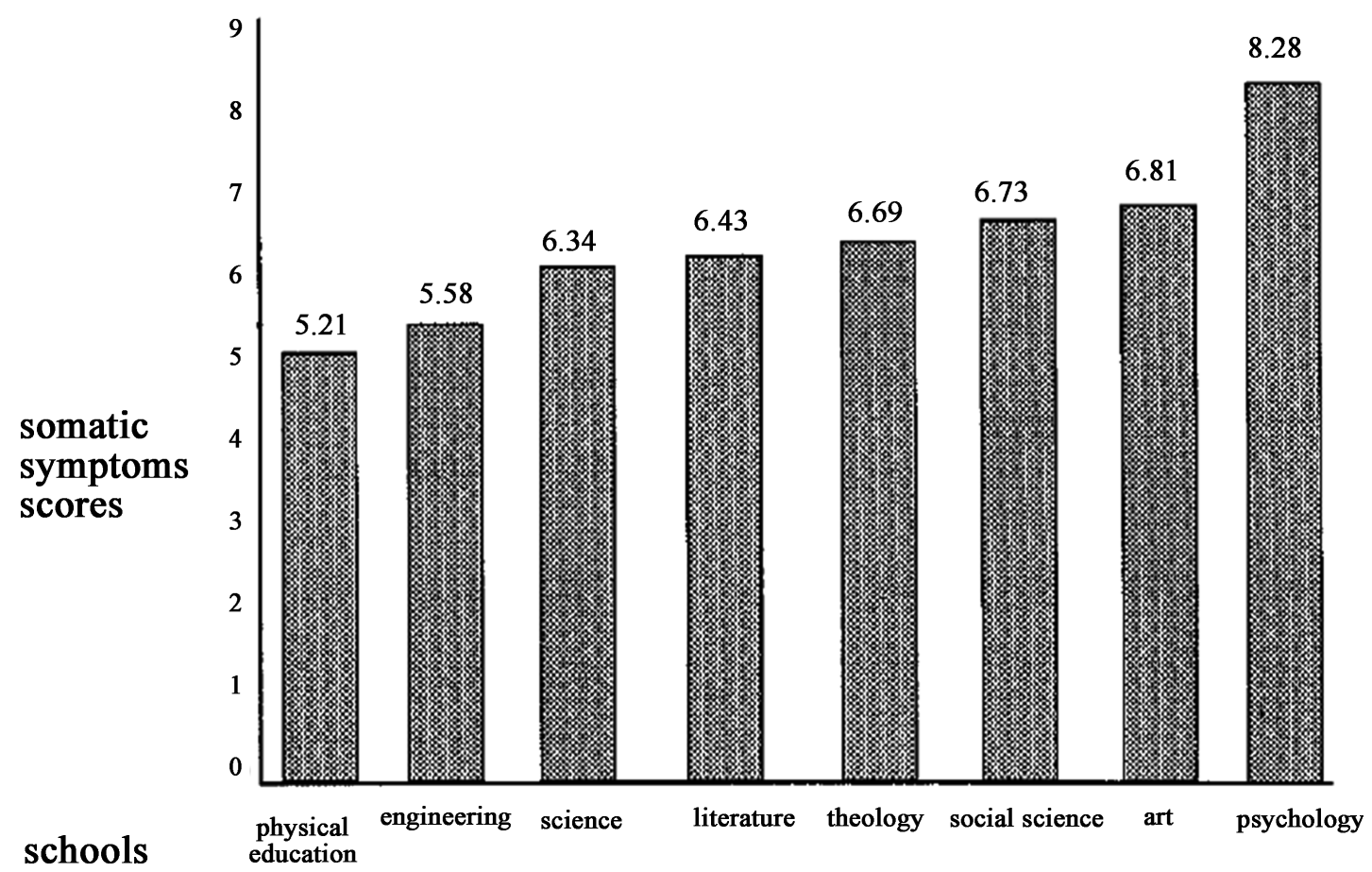

Figure 3. Comparison of physical symptoms Divided into Schools.

students have better mental health significant differences and it was also seen in all aspects of mental health such as physical symptoms and signs and symptoms of anxiety and insomnia, social dysfunction and depressive symptoms. Athletes were significantly different from the non-top $\{p<0 / 05\}$. The results are consistent with similar studies. In this study, it was found that exercise can improve mood and psychological well-being and increased confidence, and physical and mental health is increasing as well. As a result, mental health, and measures 


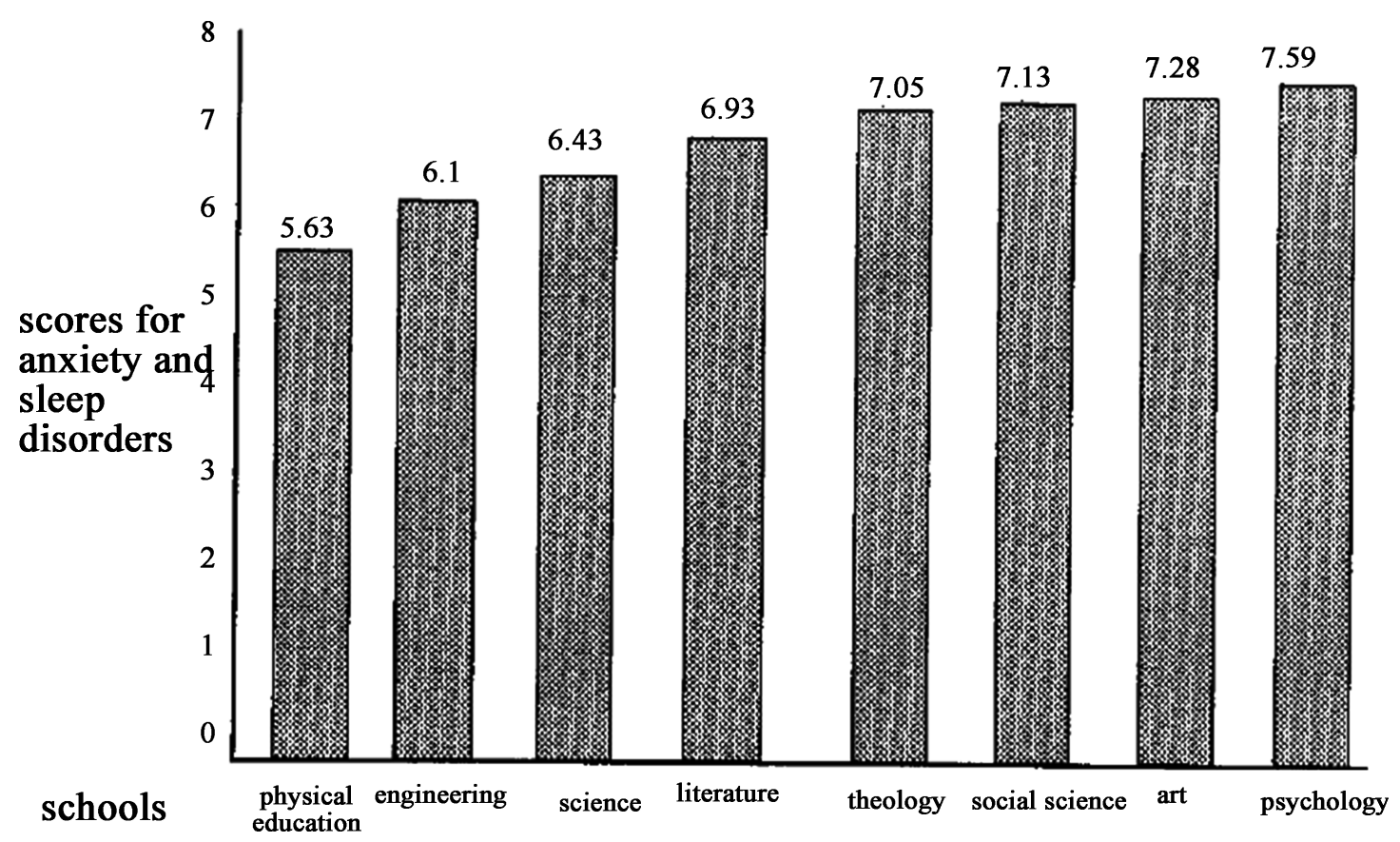

Figure 4. Comparing symptoms of anxiety and sleep disorders Divided into Schools.

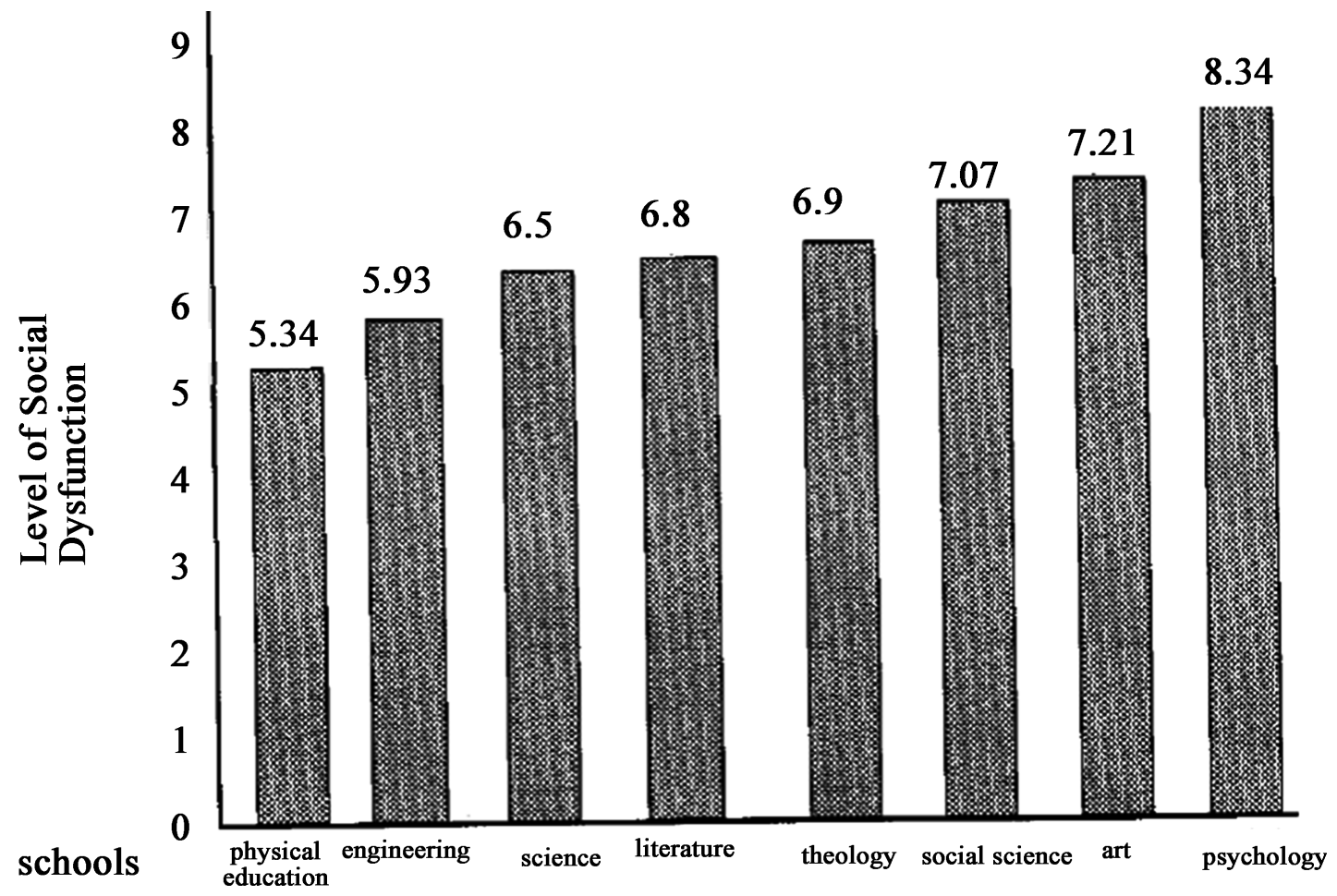

Figure 5. Comparing symptoms of social dysfunction Divided into Schools.

in four different schools are also out. As in the mental faculties Faculty of Physical Education and School Psychology in the best position is at the lowest level. The symptoms of insomnia, anxiety and dysfunction were more frequent in the School of Psychology. Depression scores were registered in the Faculty of Physical Education to be allocated to the lowest rates of depression and depressive symptoms in the highest state of the art 


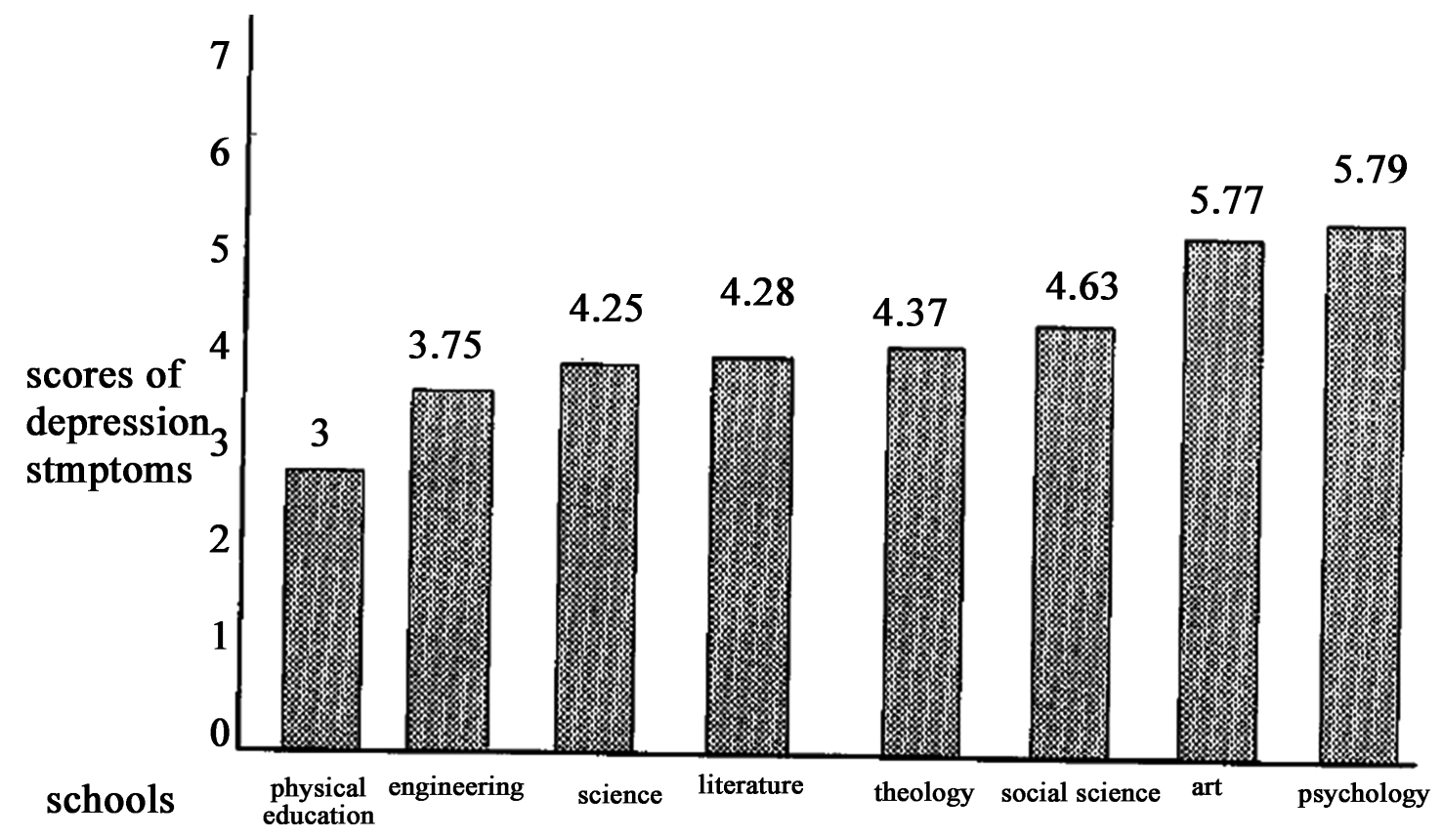

Figure 6. Comparison of symptoms of depression divided into Schools.

school is located. The results are characterized that student athletes in terms of mental health conditions are more favorable. As well as the students physical and mental health of college students are superior to others and the role of physical activity in the student's mental health shows. Hope that all students with physical outdoor activities, and prepare yourself for a healthy life.

\section{References}

Brunner, L. S., \& Suddarth, D. S. (2004). Text Book of Medical Surgical Nursing.12th Edition Company Philadelphia.

Humphreys, R. (2003). The Effect of Professional Sports on Earnings and Employment in the Services and Retail Sectors in US Cities. Regionsl Scienceand Urban Eco-Nomics, 33, 175-198. http://dx.doi.org/10.1016/S0166-0462(02)00010-8

Knechtle, B. (2004). Influence of Physical Activity on Mental Well-Being and Psychiatric Disorders. Schweiz Rundsch Med Prax, 93, 1403-1411.

Matsudo, S. et al. (2006). Evaluation of a Physical Activity Promotion Program: The Example of Agita São Paulo. Evaluation and Program Planning, 29, 301-311. http://dx.doi.org/10.1016/j.evalprogplan.2005.12.006

Pereira, A. C. et al. (2007). An in Vivo Correlate of Exercise-Induced Neurogenesis in the Adult Dentate Gyrus. Proceedings of the National Academy of Sciences of the United States of America, 104, 5638-5643.

Samad, A. et al. (2004). A Meta-Analysis of the Association of Physical Activity with Reduced Risk of Colorectal Cancer. Colorectal Disease, 7, 204-213.

McGannon, K., \& Poon, P. (2005). The Effect of Exercise on Global Selfesteem: A Quantitative Review. Journal of Sport and Exercise, 27, 311-334.

World Health Organization (2007). Mental Health: A State of Well-Being. Fact File. 